Lian Agustina Setiyaningsih, Korelasi terpaan media kie (komunikasi, informasi dan edukasi) penanggulangan hiv dan aids dengan tingkat pengetahuan pekerja seks perempuan (studi kasus pekerja seks perempuan kabupaten malang)

\title{
KORELASI TERPAAN MEDIA KIE (KOMUNIKASI, INFORMASI DAN EDUKASI) PENANGGULANGAN HIV DAN AIDS DENGAN TINGKAT PENGETAHUAN PEKERJA SEKS PEREMPUAN
}

(Studi Kasus Pekerja Seks Perempuan Kabupaten Malang)

\author{
Lian Agustina Setiyaningsih \\ Program Studi Ilmu Komunikasi FISIP Universitas Merdeka Malang \\ lian.agustinas@gmail.com
}

\begin{abstract}
This study discusses the relationship of media exposure to HIV and AIDS IEC (leafflet and stickers) to the level of knowledge of female sex workers in Malang Regency Suko localization. Media IEC is media Information, Education, Communication and leaflet and stickers that are health communication media has been running from 2006 to the present. Media leaflet and stickers is a health communications media that shape and change the knowledge of female sex workers.IEC media exposure and stickers leaflet measured from the frequency and duration of female sex workers in using the media. To measure knowledge of causes, symptoms or signs, treatments, modes of transmission and prevention of HIV and AIDS. The indicators in terms of content and the physical media IEC leaflet and stickers.

This study classified as quantitative studies that measure the correlation of the independent variable exposure to media IEC (leaflet and stickers) with the independent variable is the level of knowledge. To determine the relationship between them, this study used the instrument in the form of a questionnaire distributed to 90 female sex workers in the localization Suko. It also uses techniques of data analysis techniques Spearman Rank correlation because not distributed normally. This study proves the existence of a significant correlation between media exposure to HIV and AIDS IEC (leaflet and stickers) with the level of knowledge of female sex workers in Malang Regency Suko localization. Correlations that occur in this study is a positive correlation in which the low correlation coefficient value $(p)$ of +0.362 . The coefficient of determination (contribution) in this study is $13.7 \%$.
\end{abstract}

Key words: IEC Media Exposure, The level of Knowledge, and Female Sex Workers

\begin{abstract}
Abstrak
Penelitian ini membahas hubungan terpaan media KIE penanggulangan HIV dan AIDS (leaflet dan sticker) terhadap tingkat pengetahuan pekerja seks perempuan di lokalisasi Suko Kabupaten Malang. Media KIE adalah media Komunikasi, Informasi dan Edukasi yang berupa leaflet dan sticker. Media ini merupakan media komunikasi kesehatan sudah berjalan mulai tahun 2006 hingga saat ini. Media leaflet dan sticker merupakan media komunikasi kesehatan yang membentuk dan merubah pengetahuan pekerja seks perempuan. Terpaan media KIE
\end{abstract}


leaflet dan sticker diukur dari frekuensi dan durasi pekerja seks perempuan dalam menggunakan media tersebut. Untuk pengetahuan diukur penyebab, gejala atau tanda-tanda, cara pengobatan, cara penularan dan cara pencegahan HIV dan AIDS.

Indikator tersebut dilihat dari segi konten dan fisik media KIE leaflet dan sticker. Penelitian ini tergolong sebagai penelitian kuantitatif yang mengukur korelasi variabel bebas terpaan media KIE (leaflet dan sticker) dengan variabel tidak bebasnya tingkat pengetahuan. Untuk mengetahui hubungan di antara keduanya, penelitian ini menggunakan instrument berupa kuesioner yang disebar kepada 90 pekerja seks perempuan di lokalisasi Suko. Selain itu juga menggunakan teknik analisis data teknik korelasi Spearman Rank karena berdistribusi tidak normal. Kesimpulan studi ini membuktikan adanya korelasi yang siginifikan antara terpaan media KIE penanggulangan HIV dan AIDS (leaflet dan sticker) dengan tingkat pengetahuan pekerja seks perempuan di lokalisasi Suko Kabupaten Malang. Korelasi yang terjadi dalam penelitian ini adalah korelasi positif dimana nilai koefisien korelasinya rendah (p) sebesar $+0,385$. Koefisien determinasi (kontribusi) dalam penelitian ini adalah $13,7 \%$.

Key words: Terpaan Media KIE, Tingkat Pengetahuan, dan Pekerja Seks Perempuan.

\section{PENDAHULUAN}

Penelitian ini membahas hubungan terpaan media KIE (Komunikasi, Informasi dan Edukasi) penanggulangan HIV dan AIDS berupa leaflet dan sticker terhadap tingkat pengetahuan pekerja seks perempuan. Penelitian ini dilakukan di lokalisasi Suko yang terletak di Kabupaten Malang. Fenomena penularan HIV dan AIDS sudah menjadi bagian dari kehidupan kita. Karena penularan tidak hanya terjadi melalui transmisi seksual saja, melainkan bisa melalui jarum suntik dan air susu ibu yang terinfeksi HIV dan AIDS. Ditjen Pencegah dan Pengendalian Penyakit Kemenkes RI (2016) dari jumlah penduduk Indonesia yang hampir mencapai 240 juta jiwa, data hingga Maret 2016 jumlah penderita HIV dan AIDS atau disebut Orang Dengan HIV dan AIDS (ODHA) mencapai estimasi 276.5111 orang yang tersebar di seluruh Provinsi di Indonesia. Dengan Sebaran Data Provinsi Jawa Timur berada di peringkat kedua dengan angka mencapai lebih dari 40.551 orang. Adapun Provinsi yang mendominasi kasus ini adalah DKI Jakarta dengan 48.605 orang dan diperingkat ketiga terdapat Papua dengan kisaran angka 40.302 orang. Kabupaten Malang yang merupakan bagian dari Jawa Timur yang menduduki peringkat kedua di Indonesia. Populasi yang mudah tertular serta menularkan adalah para pekerja seks perempuan melalui transmisi seksual. Dalam kasus transmisi seksual di kalangan pekerja seks perempuan, penanggulangan satu-satunya yang sementara ini bisa dilakukan adalah dengan pengggunaan kondom. Namun, kondisi riil yang terjadi adalah target penggunaan kondom pada hubungan seks beresiko tinggi belum tercapai (Data Ditjen PP\&PL Kemenkes, 2011). Sementara di Kabupaten Malang, Komisi Pennggulangan HIV dan AIDS (KPA) Kabupaten menunjukkan jumlah pekerja seks perempuan yang terinfeksi mencapai 50 orang dengan populasi pekerja seks perempuan 1.110 orang. Jumlah tersebut bisa menjadi lebih besar 10 kali 
lipat, karena masih banyak yang belum bisa dideteksi (KPA Kabupaten Malang, 2015).

Penelitian ini memilih lokalisasi Suko, karena merupakan lokalisasi yang dijadikan parameter penanggulangan HIV dan AIDS di Malang Raya. Disamping itu, populasi di Suko juga sangat besar dengan jumlah 190 orang dan tingkat mobilisasi pekerja seks perempuannya sangat tinggi. Salah satu metode yang digunakan dalam program pendampingan adalah kampanye atau sosialisasi melalui media KIE (Komunikasi, Informasi dan Edukasi) yang dimulai pada tahun 2006 hingga saat ini.

Pada dasarnya media KIE yang beredar di kalangan pekerja seks perempuan, tidaklah diperuntukkan secara khusus untuk mereka. Bentuk dari media KIE itu sendiri berupa poster, leaflet, booklet, sticker, mug, majalah dinding dan kaos. Dalam penelitian ini, peneliti memilih dua media saja berupa leaflet dan sticker. Hal ini dikarenakan leaflet dan sticker merupakan media yang paling dekat dengan pekerja seks perempuan. Dan dari banyak macam media KIE yang beredar dan masih bertahan digunakan oleh para pekerja seks perempuan adalah leaflet dan sticker. Ukurannya yang kecil dan tidak tebal membuat media ini paling dekat dengan mereka. Di dalam leaflet berisikan pengetahuan HIV dan AIDS serta jargon pencegahan. Sedangkan dalam sticker hanya terdapat jargon pencegahannya yang sudah dikenal di kalangan umum yakni "ABC Stop". Kontennya tentang upaya pencegahan penularan HIV dan AIDS dengan penjelasan $\mathrm{A}$ adalah anda tidak melakukan seks; B adalah bersikap saling setia dengan pasangan; $\mathrm{C}$ adalah cegah dengan kondom serta Stop adalah jangan menggunakan narkoba suntik (Leaflet dan Sticker Penanggulangan HIV AIDS USAID \& FHI, 2005).

Pesan yang secara intens ditekankan pada pekerja seks perempuan adalah cegah dengan memakai kondom. Pesan yang disampaikan melalui leaflet dan sticker adalah pengetahuan tetang HIV dan AIDS serta pencegahannya. Akan tetapi dalam perjalannya hingga tahun 2011 media KIE yang dijadikan tumpuan terdekat dalam upaya perubahan perilaku kesehatan pekerja seks perempuan ternyata tidak memiliki pengaruh yang cukup signifikan. Hal ini bisa dilihat dari perkembangan jumlah pengidap Infeksi Menular Seksual (IMS) di lokalisasi Suko yang naik turun. Jumlah penderita IMS merupakan salah satu indikator untuk mengetahui pekerja seks perempuan memakai kondom atau tidak. Dari paparan data di atas, angka IMS mengalami naik turun presentasenya. Data IMS untuk menentukan peluang semakin bertambah atau berkurangnya jumlah ODHA dari kalangan pekerja seks perempuan. Hal ini dikarenakan IMS merupakan pintu masuk dari penularan HIV dan AIDS melalui transmisi seksual. Adapun data IMS pekerja seks perempuan di lokalisasi Suko dari Lembaga Paramitra 2003-2011:

Gambar I.1: Korelasi Pemakaian Kondom Dengan Angka Kejadian IMS Pada 
Pekerja Seks Perempuan Lokalisasi Suko Kabupaten Malang

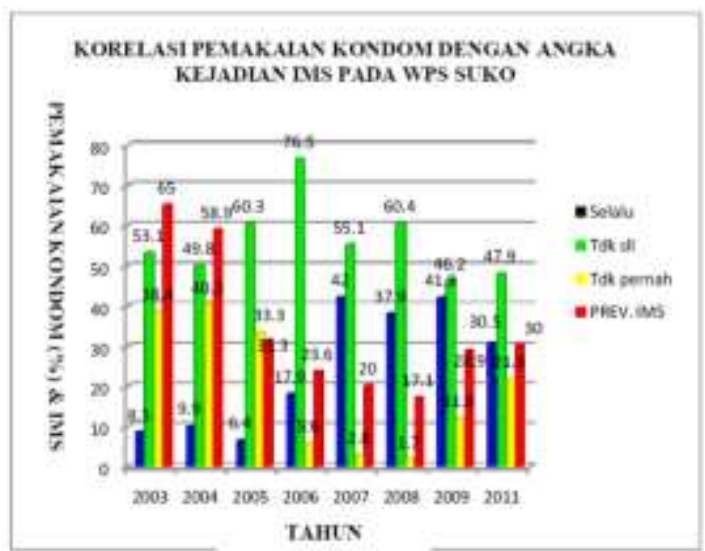

Pada dasarnya media KIE digunakan sebagai media untuk mengkampanyekan pengetahuan tentang perilaku yang aman dalam melakukan hubungan seksual sehingga dapat mengurangi penularan HIV dan AIDS. Sebagai bagian dari program penanggulangan HIV dan AIDS, media KIE diharapkan mampu memberikan efek komunikasi berupa adanya perubahan pengetahuan tentang HIV dan AIDS dan perilaku seks dari para pekerja seks perempuan, pelanggan serta komunitas beresiko tinggi yang tinggal di sekitar lokalisasi. Dalam penelitian ini, efek yang ingin diteliti adalah kognisi yaitu tingkat pengetahuan pekerja seks perempuan.

Dalam keseharian pekerja seks perempuan selalu didaulat sebagai sampah masyarakat, karena pekerjaan mereka adalah menjual tubuh. Pelabelan negatif ini tidak bisa dipandang sebelah mata, karena sudah mengakar dalam benak masyarakat. Lokalisasi merupakan tempat dimana para pekerja seks perempuan hidup dan bekerja. Sekalipun juga ada beberapa yang memperdebatkan posisi pekerja seks perempuan dalam fenomena sampah masyarakat dan profesional. Namun, terlepas dari hal tersebut, pekerja seks perempuan memiliki peran penting dalam pemotongan mata rantai penularan HIV dan AIDS. Sehingga pekerja seks perempuan juga harus memiliki pengetahuan yang baik dan benar atas HIV dan AIDS dan perilaku seks yang sehat untuk pencegahan penularannya melalui media KIE yang beredar. Hal ini dikarenakan, proses komunikasi yang terjalin di dalam kelompok atau komunitas adalah sebagai penentu paham atau tidaknya pekerja seks perempuan terhadap materi yang ada.

Fenomena di atas terkait dengan aspek komunikasi yakni efek komunikasi yang ditunjukkan melalui perilaku komunikan (pekerja seks perempuan). Peneliti akan memfokuskan pembahasan pada aspek hubungan terpaan media KIE (leaflet dan sticker) terhadap tingkat pengetahuan pekerja seks perempuan terhadap penanggulangan HIV dan AIDS. Seperti yang kita ketahui bahwa komunikasi mengandung aspek mengubah pengetahuan, sikap, pendapat atau perilaku baik secara langsung (lisan) maupun tak langsung (Effendy, 2003:24).

Dengan kata lain sebuah komunikasi yang efektif adalah dimana komunikan mengalami perubahan kognisi, afeksi, dan konatif seperti yang diinginkan oleh komunikatornya. Dalam kaitannya dengan efek, media KIE di sini digolongkan sebagai media nirmassa karena bentuk media yang akan diteliti adalah berupa sticker dan leaflet yang efeknya bukan untuk massa. Dalam penelitian terdahulu yang berjudul Hubungan Antara Keluarga dan Terpaan Media Cetak Dengan Motif Membaca Remaja Pada Majalah Penyebar Semangat yang dilakukan oleh Bambang (1995) 
menyebutkan bahwa apapun bentuk medianya terpaan media meemiliki kaitan yang erat dengan motif yang dimiliki oleh pembacanya.

Terpaan media diartikan sebagai frekuensi dan durasi penggunaan media. Sehingga terpaan media KIE (leaflet dan sticker) oleh pekerja seks perempuan di lokalisasi Suko Kabupaten Malang dapat dilihat melalui frekuensi dan durasi penggunaan media KIE. Menurut pendapat Steven M. Chaffe yang masih sejalan dengan pemikiran Lasswell, menyatakan bahwa efek media dapat dilihat dari tingkat kognisi, afeksi dan perilaku khalayak ataukomunikan. Hal tersebut bisa berupa penerimaan informasi, perasaan atau sikap, dan perilaku; atau dengan istilah lain, kognisi, afeksi, dan behavioral (konatif). Pendekatan selanjutnya adalah dengan meninjau satuan obeservasi yang dikenai efek, yaitu bisa berupa individu, kelompok, organisasi, masyarakat atau bangsa (Rahmat, 2004:218).

Sikap pekerja seks perempuan terhadap informasi tertentu dapat dibentuk melalui terpaan media KIE (leaflet dan sticker), melalui perubahan pengetahuan terlebih dahulu. Penelitian ini melihat hubungan terpaan media KIE dengan tinggi rendahnya tingkat hubungan dengan pengetahuan pekerja seks perempuan. Adapun beberapa penelitian terdahulu yang mendukung penelitian ini antara lain: pengaruh pendidikan kesehatan terhadap pengetahuan, sikap dan perilaku PSK dalam rangka pencegahan IMS di lokalisasi Gajah Kumpul Kabupaten Pati, Dilakukan oleh Dwi Lestari, FKM, UNS Solo. Hasil penelitiannya adalah terdapat pengaruh pendidikan kesehatan melalui metode ceramah dan leaflet terhadap pengetahuan, sikap dan prilaku PSK (Lestari, 2010). Keefektifan media leaflet dan sticker terhadap perubahan tingkat pengetahuan dan perilaku waria dalam upaya pencegahan HIV dan AIDS Di Himpunan Waria Solo (Hiwaso), Astri Fidyaningsih, FKM, Universitas Muhammadyah Surakarta. Hasilnya: ada perbedaan tingkat pengetahuan sebelum dan sesudah diberi media leaflet dan sticker di Hiwaso (Fidyaningsih, 2011). Dari kajian tersebut, ternyata terdapat celah atau kekosongan wilayah kajian yakni, hubungan terpaan media KIE tentang penaggulangan HIV dan AIDS terhadap tingkat pengetahuan pekerja seks perempuan. Dari fenomena komunikasi di atas, maka pernyataan permasalahannya adalah belum diketahuinya hubungan terpaan media KIE dengan tingkat pengetahuan pekerja seks perempuan di lokalisasi Suko Kabupaten Malang.

\section{TINJAUAN PUSTAKA}

\section{Komunikasi Kesehatan}

Model komunikasi Lasswell dijadikan dasar dalam menguraikan fenomena komunikasi di dalam mencari hubungan terpaan media KIE (leaflet dan sticker) dengan tingkat pengetahuan pekerja seks perempuan. Seperti yang telah dijelaskan pada latar belakang, bahwa menurut Lasswell, proses komunikasi tersebut terjadi ketika terdapat unsur-unsur komunikasi dimana dalam penelitian ini, who dapat dinyatakan pada Lembaga Paramitra selaku LSM pendamping, says what untuk pesan penggunaan kondom, in which channel ditujukan pada leaflet dan sticker sedangkan to whom adalah pekerja 
seks perempuan dan with what effect adalah tinggi rendahnya tingkat pengetahuan. Sehingga jelas, dari penjelasan tersebut dalam penelitian ini membahas terkait permasalahan komunikasi (Mulyana, 2001:132-133). Littlejohn juga mengutarakan bahwa model yang diutarakan Lasswell ini secara jelas mengelompokkan elemen-elemen mendasar dari komunikasi ke dalam lima elemen yang tidak bisa dihilangkan salah satunya (Littlejohn, 1996:334).

Berangkat dari pernyataan Fiske, bahwa model komunikasi Lasswell merupakan model yang melihat komunikasi sebagai transmisi pesan. Dengan kata lain, model ini mengungkap isu tentang "efek" dan bukannya "makna". Komunikasi akan timbul sebuah efek jika pesan disampaikan atau dikonsumsi secara berulang-ulang (terpaan). Identifikasi yang dilakukannya terhadap dua fungsi dari komunikasi. Pertama adalah kemampuan kemampuan media memberikan informasi yang berkaitandengan lingkungan di sekitar kita, yang dinamakannya sebagai surveillance. Kedua, adalah kemampuan media memberikan berbagai pilihan dan alternatif dalam penyelesaian masalah yang dihadapi masyarakat, yang dinamakanya sebagai fungsi correlation (Fiske, 2011:46).

Dalam komunikasi kesehatan, model komunikasi Laswell melibatkan metode komunikasi yakni penyuluhan yang merupakan solusi untuk komunikasi kelompok. Penyuluhan dianggap sebagai komunikasi transaksional dan simbolik yang bertujuan untuk tukar menukar informasi, menetapkan pengetahuan, serta mengubah sikap dan perilaku komunikan (Nasution, 1990:12).
Berkaitan dengan komunikasi kelompok, bahwa penyuluhan dilakukan terhadap kelompok, dimana menekankan pada tingkah laku dan pola interaksi komunikasi individu-individu dalam diskusi kelompok kecil. Dari interaksi yang terjalin menyebabkan terjadinya dinamika dalam internal kelompok (Suprapto, 2004:33).

Proses komunikasi merupakan suatu perubahan atau rangkaian tindakan serta peristiwa selama beberapa waktu dan yang menuju suatu hasil tertentu. Dengan demikian mulai proses menciptakan informasisampai memahami informasi merupakan proses komunikasi secara umum. Dimana proses tersebut dibagi menjadi dua yakni primer (tatap muka) dan sekunder (media) (Liliweri, 1991:42). Proses komunikasi sekunder sebagai proses penyampaian pesan oleh seseorang kepada orang lain dengan menggunakan alat atau saranan sebagai media kedua setelah memakai lambang sebagai media pertama. Yang dimaksud lambang sebagai media pertama dalam proses komunikasi adalah bahasa (Sutaryo, 2005:21).

\section{Terpaan Media (Media Exposure)}

$\begin{array}{ccr}\text { Media } & \text { exposure } & \text { dapat } \\ \text { dioperasionalkan } & \text { sebagai frekuensi }\end{array}$
individu dalam menggunakan media. Selain itu terpaan media berusaha mencari data khalayak atau komunikannya tentang penggunaan media, baik jenis media, frekuensi penggunaan maupun durasi penggunaan (longevity). Shore memberikan definisi sebagi berikut : Media exposure is more complicated than acces because is ideal not only with what her a person is within physical (range of particular medium) but also whether 
person is actually expose to message. Exposure is hearing, seeing, reading, or most generally, experiencing with at least a minimal amount of interest the media message. The exposure might occure to an individual or group level (Pratoyo, 1995:23).

Menurut Rosengren, penggunaan media sendiri terdiri dari jumlah waktu yang digunakan dalam berbagai media, jenis isi media, media yang dikonsumsi atau dengan media secara keseluruhan (Rahmat, 2004:26). Terpaan merupakan kegiata mendengar, melihat dan membaca pesan-pesan dalam media ataupun pengalaman dan perhatian terhadap pesan tersebut yang terjadi pada individu maupun kelompok.

Dalam kajian psikologi komunikasi (Rahmat, 2004:52-53), sifat menonjol yang mendukung terpaan media adalah: gerakan, intensitas stimuli, kebaruan dan perulangan. Peneliti menyimpulkan bahwa untuk mengukur terpaan media adalah dengan melihat frekuensi dan durasi penggunaan media. Sehingga dalam penelitian ini indikator dari variabel terpaan adalah berupa frekuensi dan durasi dari penggunaan media oleh komunikan.

\section{Efek Penggunaan Media KIE dan Tingkat Pengetahuan Pekerja Seks Perempuan}

Bandura, manusia belajar bukan saja dari pengalaman langsung, tetapi dari peniruan atau peneladanan (modeling). Perilaku merupakan hasil faktor-faktor kognitif dan lingkungan. Artinya, manusia mampu memiliki keterampilan tertentu, bila terdapat jalinan positif antara stimuli yang mereka amati dan karakteristik individu. Proses belajar sosial dalam empat tahapan proses: proses perhatian, proses pengingatan (retention), proses reproduksi motoris, dan proses motivasional (Rahmat, 2004:20).

Perilaku merupakan bagian dari sikap manusia. Disebutkan bahwa terdapat tiga komponen sikap yakni kognisi, afeksi dan perilaku. Ketiga komponen tersebut berawal dari stimulus dan dipengaruhi oleh faktor lingkungan. Kognisi merupakan bentuk keyakinan; afeksi adalah perasaan dan emosi; dan perilaku adalah tindakan untuk mencapai tujuan. Sikap terbentuk dengan mencari kesesuaian antara keyakinan dengan perasaan terhadap objek (Invancevich\&Robert, 2006:26-27).

Namun, penelitian ini akan membatas dengan melihat tingkat pengetahuan saja. Hal ini sesuai dengan domain yang diukur dari hasil komunikasi kesehatan adalah berupa pengetahuan (knowlagde), sikap (attitude) dan praktik (practice) (Fitriani, 2011:192).

Menurut Notoatmojo (2003) Pengindraan terjadi melalui panca indra manusia yakni indra penglihatan, pendengaran, penawaran rasa, dan peraba. Sebagian besar pengetahuan manusia diperoleh melalui mata dan telinga. Pengetahuan atau kognitif merupakan domain yang sangat penting dalam membentuk tindakan seseorang (overt behavior). Sedangkan dalam Fitriani (2011) pengetahuan meruapakan suatu kemampuan untuk menjelaskan secara benar tentang objek yang diketahui, dan dapat mengitepretasikan materi secara benar. Juga menjelaskan pengetahuan yang tercakup dalam domain kognitif mempunyai tingkatan: Tahu (know), 
Memahami (comprehension), Aplikasi (application), dan Analisis (analysist), Sintesis, Evaluasi.

Pengetahuan terbentuk berdasarkan kepercayaan seseorang mengenai apa yang berlaku atau apa yang benar bagi objek sikap. Ketika kepercayaan telah terbentuk, maka menjadi dasar pengetahuan seseorang mengenai harapan atas objek tertentu. Begitu juga dengan pengalaman dan prediksi yang dimiliki akan merangkai pengetahuan (Azwar, 2010:25).

Menurut Notoatmojo (2003) pengetahuan dapat dipengaruhi oleh beberapa faktor, yakni: umur, pendidikan, pekerjaan dan sumber informasi. Berdasarkan teori pengetahuan, indikator yang bisa digunakan untuk mengukur pengetahuanterhadap kesehatan dapat dilihat melalui pengetahuan tentang sakit dan penyakit yang meliputi: penyebab penyakit, gejala, cara pengobatan/akses mencari pengobatan, cara penularannya dan cara pencegahan. Berdasarkan indikator di atas, tingkat pengetahuan dalam penelitian ini dapat diukur melalui:

a. Penyebab HIV dan AIDS

b. Gejala atau tanda-tanda HIV dan AIDS

c. Bagaimana cara pengobatan, atau kemana mencari pengobatan HIV dan AIDS

d. Bagaimana cara penularan dan pencegahan HIV dan AIDS

Indikator fisik dari media KIE didapat dari pilihan warna dan gambar di media tersebut.

\section{Media KIE bagi Pekerja Seks Perempuan}

Media KIE dianggap sebagai media pendidikan kesehatan, yang juga diartikan sebagai alat bantu pendidikan. Media KIE merupakan saluran atau media yang menjebatani pekerja seks perempuan untuk meningkatkan pengetahuan agar bisa melakukan pemotongan penularan HIV dan AIDS. Meski media KIE ini bukan media yang khusus diperuntukkan bagi pekerja seks perempuan, namun media KIE ini sudah beredar luas di lokalisasi dan dikonsumsi oleh mereka dalam kehidupan sehari-hari. Konten media KIE berupa liftlet dapat dalam bentuk kalimat maupun gambar, atau kombinasi. Sedangkan sticker bentuknya berupa lembaran kecil yang bisa ditempelkan, isinya pun sama dengan leaflet (Fitriani, 2011: 176).

Media KIE juga merupakan alat bantu untuk membangkitkan perhatian dan menjadi sarana untuk mengingat-ingat pesan. Sehingga isi dari media KIE sangat menentukan efek yang akan timbul. Dalam media KIE penanggulangan HIV dan AIDS yangberbentuk leaflet, isi pesannya berupa: pengertian HIV dan AIDS, himbauan menjaga diri, sikap beresiko dan tidak beresiko tertular, pencegahan dan jargonnya, cara mengetahui penularan, serta pengobatan jika tertular. Sedagkan sticker hanya berisi tentang jargon pencegahan HIV dan AIDS (ABC StoP). Selain pengetahuan yang akan dibahas dalam penelitian ini, media KIE juga dilihat secara fisik yakni dari segi pilihan gambar dan pilihan warna yang dipakai dalam media KIE.

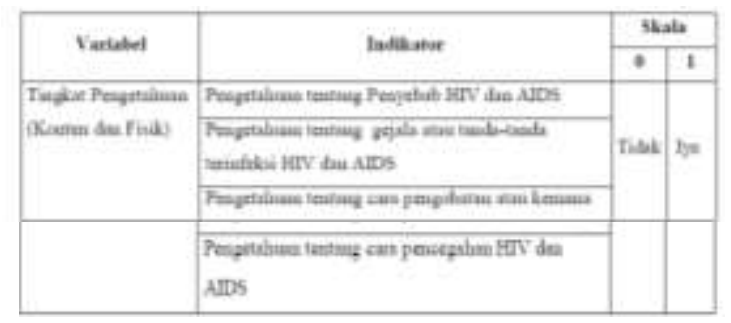

\section{Hipotesis}


H0: Tidak terdapat hubungan yang positif dan signifikan antara terpaan media KIE penanggulangan HIV dan AIDS dengan tingkat pengetahuan pekerja seks perempuan.

H1: Terdapat hubungan yang positif dan signifikan antara terpaan media KIE penanggulangan HIV dan AIDS dengan tingkat pengetahuan pekerja seks perempuan.

Berdasarkan rumusan hipotesis di atas maka dapat digambarkan model hubungan antar variabel sebagai berikut:

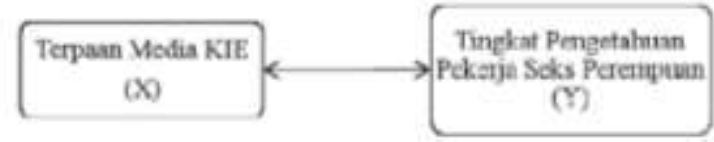

Gambar Model Antar Variabel

\section{METODE PENELITIAN}

Penelitian ini menggunakan metode kuantitatif, karena hendak mengukur variabel-variabel dan tingkat hubungan antara variabel satu terhadap yang lainnya. Pendekatan kuantitatif adalah suatu pendekatan yang berperspektif etik. (Hamidi, 2010:125)

\section{Definisi operasional}

Variabel independent (X) terpaan media KIE penanggulangan HIV dan AIDS. Indikator dari variabel terpaan media KIE adalah frekuensi dan durasi pekerja seks perempuan.

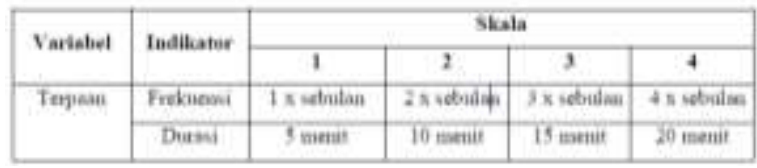

Tabel Variasi Variabel Terpaan

Terpaan adalah hasil kali dari indikator frekuensi dengan durasi. Sehingga sebaran nilai dari variabel terpaan dapat dilihat dari tabel dibawah ini:
Sedangkan penilaian terpaan media KIE berdasarkan sebaran nilai variabel adalah:

\begin{tabular}{|c|c|c|c|c|c|}
\hline \multicolumn{2}{|c|}{ Indokator } & \multicolumn{4}{|c|}{ Frekuensi (kali per bulan) } \\
\cline { 3 - 6 } \multicolumn{2}{|c|}{} & $\mathbf{1}$ & $\mathbf{2}$ & $\mathbf{3}$ & $\mathbf{4}$ \\
\hline \multirow{4}{*}{$\begin{array}{c}\text { Durasi } \\
\text { (menit) }\end{array}$} & $\mathbf{5}$ & 5 & 10 & 15 & 20 \\
\cline { 2 - 6 } & $\mathbf{1 0}$ & 10 & 20 & 30 & 40 \\
\cline { 2 - 6 } & $\mathbf{1 5}$ & 15 & 30 & 45 & 60 \\
\cline { 2 - 6 } & $\mathbf{2 0}$ & 20 & 40 & 60 & 80 \\
\hline
\end{tabular}

$$
\begin{aligned}
\text { Skala Interval } & =\frac{m-n}{b} \\
& =\frac{80-5}{3} \\
& =25
\end{aligned}
$$

Variabel dependent (Y), dilhat dari tingkat pengetahuan pekerja seks perempuan. Tingkat pengetahuan berkaitan dengan pikiran atau penalaran dari tidak tahu, tidak mengerti, bingung menjadi jelas. Skala yang digunakan untuk mengukur tingkat pengetahuan pekerja seks perempuan adalah berupa skala Guttman. Skala ini mengukur dengan menggunakan pertanyaan yang jawabannya adalah IyaTidak. Pembuatan kuesioner didasarkan pada variasi variabel dibawah ini:

\begin{tabular}{|c|c|}
\hline Skor & Intepretasi \\
\hline $5-29$ & Terpaan Rendah \\
\hline $30-54$ & Terpaan Sedang \\
\hline $55-80$ & Terpaan Tinggi \\
\hline
\end{tabular}

Penilaian di setiap variabel dikategorikan dengan cara menggunakan rumus rentang skala (RS) 


$$
\text { Skala Interval }=\frac{m-n}{b}
$$

Keterangan :

m -skor tertinggi yang mungkinterjadi

$\mathrm{n}=$ skor terendah yang mungkinterjadidibentuk

$b=$ jumlah skala penilaian yang ingin dibentuk

Hasil pengisisan kuisioner dikategorikan tinggi, rendah dan sedang.

\begin{tabular}{|c|c|}
\hline Skor & Intepretasi \\
\hline $0-10$ & Pengetahuan Rendah \\
\hline $11-20$ & Pengetahuan Sedang \\
\hline $21-30$ & Pengetahuan Tinggi \\
\hline
\end{tabular}

\section{Populasi dan Sample}

Jumlah populasinya adalah 116 pekerja seks perempuan. Karena jumlah populasi yang cukup besar, maka ditentukan sejumlah sampel yang akan diteliti sebagai responden dengan menggunakan rumus Taro Yamane. Dengan menetapkan tingkat kesalahan atau taraf signifikansi sebesar 5\% atau 0,05 maka ukuran sampel yang digunakan adalah sebagai berikut:

$$
\begin{aligned}
n & =\frac{N}{N d^{2}+1} \\
& =\frac{116}{(116)(0,05)^{2}+1} \\
& =\frac{116}{(116)(0,0025)+1} \\
& =\frac{116}{0,29+1} \\
& =\frac{116}{1,29} \\
& =89,92 \cong 90
\end{aligned}
$$

Jadi sample yang digunakan dalam penelitian ini berjumlah 90 pekerja seks perempuan di lokalisasi Suko.
Penelitian ini menggunakan model pengujian validitas prediktif. Instrumen disebut valid jika terdapat korelasi positif antar variabel. Teknik korelasi yang digunakan adalah teknik korelasi product moment (Kriyantono, 2010:138).

Menurut Imam Gozali, uji reliabilitas dan uji validitas dapat dilakukan dengan program SPSS dengan uji statistik Cronbach's Alpha.Suatu konstruk atau variabel dikatakan reliabel jika uji statistik SPSS memberikan nilai >0,60 (Riyanto, 2008:69). Dimana analisis data menggunakan SPSSversi 17.0. Apabila populasi berdistribusi normal maka digunakan statistik parametris sebagai teknik analisis data, sedang apabila populasi berdistribusi tidak normal maka digunakan statistik non parametris (Sugiyono, 1999:66).

Uji normalitas dilakukan dengan teknik Kolmogorov-Smirnov. Metode ini dirancang untuk menguji keselarasan pada data yang kontinyu. Hipotesis yang diuji adalah:

H0: Sampel berasal dari populasi berdistribusi normal

H1: Sampel tidak berasal dari populasi berdistribusi normal

Pengambilan kesimpulan pada pengujian hipotesis tersebut didasarkan pada kriteria sebagai berikut:

-Jika signifikansi yang diperoleh $<\alpha$, maka tolak H0 (sampel berasal dari populasi yang berdistribusi normal)

- Jika signifikansi yang diperoleh $>\alpha$, maka terima HO (sampel bukan berasal dari populasi yang berdistribusi normal) (Sulaiman, 2004:18).

\section{Pengujian Instrument}




\begin{tabular}{|c|c|}
\hline Interval & Tingkat Hubungan \\
\hline $0,00-0,199$ & Sangat Rendah \\
\hline $0,20-0,399$ & Rendah \\
\hline $0,40-0,599$ & Sedang \\
\hline $0,60-0,799$ & Kuat \\
\hline $0,80-1,00$ & Sangat Kuat \\
\hline
\end{tabular}

Tabel Pedoman Intepretasi Terhadap Koefisien Korelasi

\section{Hasil dan Pembahasan}

Hasil Uji Validitas dan Uji Reliabilitas Variabel X (Terpaan Media KIE)

Pada variabel terpaan media menggunakan 4 item pertanyaan, 2 pertanyaan untuk mengetahui frekuensi dan durasi penggunaan media leaflet dan 2 pertanyaan untuk mengetahui frekuensi dan durasi penggunaan media sticker. Pengujian validitas dan reliabilitas dilakukan terhadap 30 responden, dengan nilai koefisien korelasi pada table (rt) adalah 0,361. Hasil pengolahan data pada uji validitas terhadap masing-masing item adalah sebagai berikut:

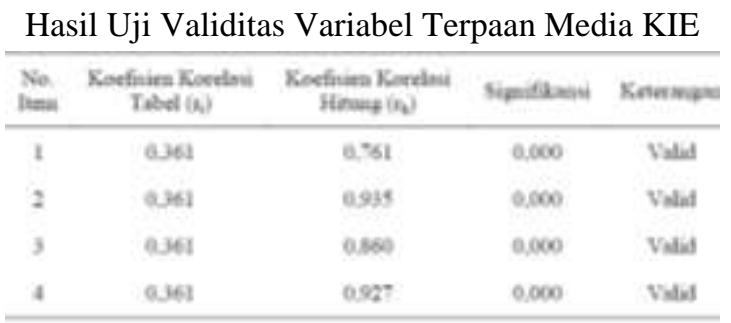

Koefisien korelasinya diperoleh rh>rt pada seluruh item. Maka seluruh item pernyataan variabel terpaan media KIE (X) dinyatakan valid. Kemudian untuk melihat validitas item berdasarkan signifikansinya, ditemukan bahwa signifikansi seluruh item bernilai 0,000 atau dibawah 0,05 , artinya seluruh item pertanyaan kuesioner terpaan media KIE (leaflet dan sticker) juga dinyatakan valid.

Hasil Uji Reliabilitas Variabel Terpaan Media KIE

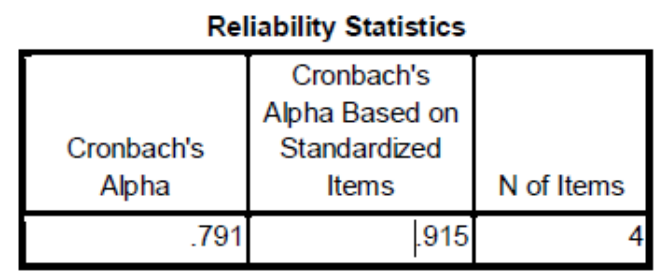

Nilai reliabilitas menunjukkan 0,791, artinya lebih besar dari 0,60. Sehingga variabel terpaan media KIE penanggulangan HIV dan AIDS bisa dinyatakan reliabel atau memiliki tingkat keandalan yang tinggi.

\section{Hasil Uji Validitas dan Uji Reliabilitas Variabel $Y$ (Tingkat Pengetahuan Pekerja Seks Perempuan)}

Pada variabel pengetahuan menggunakan 30 item pernyataan, 15 pernyataan untuk mengetahui pengetahuan tentang konten media KIE dan 15 pertanyaan untuk mengetahui pengetahuan tentang fisik media KIE. Pengujian validitas dan reliabilitas dilakukan terhadap 30 orang responden, dengan nilai koefisien korelasi pada table (rt) adalah 0,361. Dari hasil pengolahan data tersebut, terlihat bahwa validitas item pernyataan berdasarkan koefisien korelasinya diperoleh $\mathrm{rh}>\mathrm{rt}$ pada seluruh item. Maka seluruh item pernyataan variabel tingkat pengetahuan (Y) dinyatakan valid. Ditemukan bahwa signifikansi seluruh item bernilai dibawah 0,05 , yang berarti seluruh item tersebut memiliki nilai yang signifikan. Hal ini menguatkan pengujian berdasarkan koefisien korelasi productmoment.

Selanjutnya, untuk hasil uji reliabilitas terhadap variabel tingkat pengetahuan ditunjukkan pada tabel di bawah ini: 
Hasil Uji Reliabilitas Variabel Pengetahuan HIV dan AIDS Pekerja Seks Perempuan Reliability Statistics

\begin{tabular}{|r|r|r|}
\hline $\begin{array}{c}\text { Cronbach's } \\
\text { Alpha }\end{array}$ & $\begin{array}{c}\text { Cronbach's Alpha Based on } \\
\text { Standardized Items }\end{array}$ & N of Items \\
\hline .954 & .957 & 30 \\
\hline
\end{tabular}

Nilai reliabilitas dengan menggunakan Cronbach's Alpha menunjukkan angkan 0,954, artinya nilai tersebut lebih besar dari 0,60 bahkan mendekati 1. Sehingga variabel tingkat pengetahuan (Y) bisa dinyatakan sangat reliabel atau memiliki tingkat keandalan yang sangat tinggi.

\section{Karakteristik Responden}

Distribusi karakteristik usia responden paling banyak berkisar 25-39 tahun. Sedangkan pendidikan terbanyak dari responden adalah SD, sebanyak $48 \%$ pendapatan responden kurang dari 2 juta rupiah dengan lama bekerja 52\% kurang dari 1 tahun. Distribusi Variabel X dan Y, hubungan antara terpaan rata-rata mediaKIE berupa leaflet dan sticker dengan tingkat pengetahuan adalah sebesar 51, $1 \%$. Hubungan yang bisa digambarkan adalah pekerja seks perempuan mendapat terpaan rata-rata dari media KIE leaflet dan sticker sedang dan memiliki tingkat pengetahuan yang tinggi.

Hasil uji hipotesis, teknik yang digunakan adalah sperman rank karena populasi tidak berdistribusi normal. Analisis data dilakukan menggunakan SPSS, dan diperoleh angka koefisien korelasi Spearman Rank (p) sebesar 0,385, sebagaimana dapat dilihat pada tabel berikut:

\begin{tabular}{|c|c|c|c|c|}
\hline & & & $\mathrm{x}$ & $y$ \\
\hline \multirow[t]{6}{*}{ Bpeaminabite } & \multirow[t]{3}{*}{ Terpain } & Conchish Genticient & Toro & $\frac{1}{3105}$ \\
\hline & & Sou Q Q taned) & & .000 \\
\hline & & N & 90 & $\infty 0$ \\
\hline & \multirow[t]{3}{*}{ Tingkat Pergemahium } & Conelroon Coeffoient & 385 & 1000 \\
\hline & & Sy, gataled) & 000 & \\
\hline & & N & 90 & $\infty 0$ \\
\hline
\end{tabular}

Tabel korelasi menunjukkan hubungan dua variabel, arah hubungan dan besarnya hubungan tersebut. Untuk mengetahui ada tidaknya hubungan antara kedua variabel maka dilakukan interpretasi terhadap nilai korelasi dan hipotesis operasional sebagai berikut:

H0: $\mathrm{p}=0$, Tidak terdapat hubungan yang

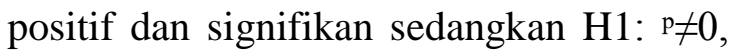
Terdapat hubungan yang positif dan signifikan. Dengan ketentuan apabila taraf signifikansi < 0, 05 maka $\mathrm{H} 1$ diterima, yang berarti bahwa kedua variabel memiliki hubungan yang signifikan. Sedangkan apabila taraf signifikansi > 0, 05 maka H1 ditolak yang berarti bahwa hubungan kedua variabel tidak signifikan.

Variabel $\mathrm{X}$ berkontribusi sebesar $13,7 \%$ terhadap tingkat pengetahuan pekerja seks perempuan. Sedangkan $86,3 \%$ tingkat pengetahuan pekerja seks perempuan dijelaskan oleh variabel lain. Variabel lain berupa usia, pendidikan, pendapatan, dan lama bekerja di lokalisasi.

Sedangkan hasil uji signifikansi menunjukkan angka $\mathrm{t}$ hitung $=3,737$, sedangkan angka $\mathrm{t}$ tabel untuk $\mathrm{n}=90(\mathrm{df}=$ 88) adalah 2, 00062. Karena $t$ hitung $>t$ tabel yaitu 3,737>2,000, maka dapat diartikan bahwa hubungan antara terpaan media KIE penanggulangan HIV dan AIDS (leaflet dan sticker) dengan tingkat pengetahuan pekerja seks perempuan adalah signifikan. Sehingga apa yang terjadi pada sampel (90 responden) bisa diberlakukan untuk populasi responden).

\section{Pembahasan}

Besarnya hubungan antara terpaan media KIE penanggulangan HIV dan AIDS (leaflet dan sticker) dengan tingkat 
pengetahuan pekerja seks perempuan didapat sebesar $+0,385$. Hal ini menunjukkan bahwa arah korelasi positif, artinya bahwa semakin tinggi terpaan media KIE maka semakin tinggi tingkat pengetahuan pekerja seks perempuan. Terpaan media bisa dilihat dari frekuensi dan durasi penggunaan media itu sendiri. Dalam penelitian ini, pengukuran terpaan media adalah melalui frekuensi dan durasi pekerja seks perempuan dalam menggunakan media leaflet dan sticker. Dengan kata lain melihat berapa kali dalam sebulan pekerja seks perempuan menggunakan media leaflet dan sticker, sekaligus berapa lama mereka menggunakan media tersebut.

Dari hasil penelitian menunjukkan bahwa sebagian besar responden pekerja seks perempuan mendapat terpaan rendah dari media KIE leaflet dan sticker. Data yang diperoleh dari 90 responden yang mengisi kuesioner, terpaan leaflet tinggi sebanyak $10 \%$, sedang $54 \%$ dan rendah $36 \%$. Sedangkan sticker terpaan tinggi sebanyak $4 \%$, sedang $56 \%$ dan rendah $40 \%$. Sedangkan jika dirata-rata, terpaan media leaflet dan sticker bisa terlihat $43 \%$ yang mendapat terpaan rendah, $51 \%$ terpaan sedang dan sisanya adalah terpaan tinggi sebanyak 6\%. Dari data tersebut, bisa diketahui bahwa rata-rata pekerja seks perempuan mendapat terpaan sedang dari media leaflet dan sticker. Hal ini juga bisa dilihat dari lama mereka bekerja di lokalisasi Suko, yakni sebagian besar responden yang menjawab kurang dari satu tahun bekerja sebanyak 52\%. Jika dilihat dari dua hal tersebut terdapat korelasi antara terpaan media leaflet dan sticker yang sedang dengan lama mereka bekerja di Suko.

Bila dilihat dari hasil analisis tingkat pengetahuan responden $90 \%$ adalah tinggi, $10 \%$ memiliki tingkat pengetahuan sedang, dan tidak ada responden yang tingkat pengetahuannya rendah. Bahwa jika dilihat dari presentase yang tinggi responden dapat melakukan intepretasi materi secara benar tentang obyek yang mereka ketahui. Sedangkan jika dihubungkan dengan teori pengetahuan yang lainnya, bahwa sebenarnya pengetahuan dipengaruhi oleh faktor umur, pendidikan, pekerjaan dan sumber informasi. Dari data sebagian besar usia responden adalah 25-29 tahun dengan presentase $28 \%$ yang berjumlah 25 orang. Dalam hal pendidikan kecenderungan reponden adalah Sekolah Dasar (SD) dengan presentase 54\%. Dan mereka yang menjawab pendapatan kurang dari dua juta sebanyak $48 \%$. Dengan adanya data yang terpapar, maka pernyataan di atas tidak bisa diberlakukan dalam penelitian ini. Seperti yang terpapar oleh data bahwa sebagian besar responden usianya masih muda, pendidikannya juga tidak tinggi dan pendapatan mereka juga tidak banyak, akan tetapi tingkat pengetahuan mereka tinggi.

Hubungan terpaan leaflet dengan tingkat pengetahuan tergambarkan sebesar $55,6 \%$, yaitu terpaan leaflet sedang dan tingkat pengetahuan mereka tinggi. Untuk terpaan sticker,sebesr $544 \%$ sedangkan Terpaan rata-ratanya adalah $51,1 \%$. Meskipun dalam penelitian ini, telah terbukti bahwa terdapat hubungan antara terpaan media KIE penanggulangan HIV dan AIDS (leaflet dan sticker) dengan tingkat pengetahuan pekerja seks 
perempuan. Akan tetapi, korelasinya rendah. Hal ini bisa dijelaskan melalui angka 0,385 dan melihat hasil analisis yang mengatakan bahwa pekerja seks perempuan rata-rata mendapatkan terpaan sedang, namun pengetahuan mereka tirnggi.

Hubungan terpaan media KIE penanggulangan HIV dan AIDS (leaflet dan sticker) bisa menjelaskan pengaruh di antara keduanya. Dimana seperti yang terpapar di atas, bahwa terpaan media KIE (leaflet dan sticker) memiliki pengaruh terhadap tingkat pengetahuan pekerja seks perempuan sebesar $13,7 \%$. Sedangkan $86,3 \%$ tingkat pengetahuan dipengaruhi oleh usia, pendapatan, tingkat pendidikan dan lama pekerja seks perempuan bekerja di lokalisasi Suko. Selain terpaan media, ternyata usia, pendapatan, tingkat pendidikan dan lama bekerja juga memiliki pengaruh dominan dalam membentuk tingkat pengetahuan pekerja seks perempuan. Semakin muda usia pekerja seks perempuan maka semakin tinggi tingkat pengetahuan meskipun terpaan leaflet dan stickernya rendah. Begitu juga dengan pendapatan dan pendidikan yang rendah, ternyata tidak membuat tingkat pengetahuan mereka rendah pula. Sedangkan untuk lama bekerja di lokalisasi Suko juga begitu, bahwa meskipun mereka belum lama bekerja di lokalisasi Suko namun tingkat pengetahuan mereka tinggi.

Penelitian ini menunjukkan adanya hubungan yang signifikan antara terpaan media KIE penanggulangan HIV dan AIDS (leaflet dan sticker) dengan tingkat pengetahuan pekerja seks perempuan. Hal ini bisa dilihat angka $\mathrm{t}$ hitung $=3,737$, sedangkan angka t tabel untuk $\mathrm{n}=90(\mathrm{df}=$ 88) adalah 2,000. Karena thitung $>\mathrm{t}$ tabel yaitu 3,737>2,000, maka dapat diartikan bahwa hubungan antara terpaan media KIE penanggulangan HIV dan AIDS (leaflet dan sticker) dengan tingkat pengetahuan pekerja seks perempuan adalah signifikan. Disamping itu korelasi yang terjadi dalam penelitian ini adalah korelasi positif dimana nilai koefisien korelasinya rendah sebesar $+0,385$. Sedangkan koefisien determinasi (kontribusi) dalam penelitian ini adalah $13,7 \%$, yang berarti variabel terpaan media KIE penanggulangan HIV dan AIDS (leaflet dan sticker) berkontribusi sebesar $13,7 \%$ terhadap tingkat pengetahuan pekerja seks perempuan. Yang membedakan kedua penelitian terdahulu dengan hasil penelitian kali ini adalah tingkat signifikansi pengaruh atau hubungan antar variabelnya.

\section{PENUTUP}

\section{Kesimpulan}

Berdasarkan hasil penelitian dan pembahasan, maka dalam penelitian ini dapat ditarik kesimpulan sebagai berikut:

1. Studi ini membuktikan adanya korelasi antara terpaan media KIE penanggulangan HIV dan AIDS (leaflet dan sticker) dengan tingkat pengetahuan pekerja seks perempuan di lokalisasi Suko Kabupaten Malang.

2. Terpaan media KIE juga memiliki pengaruh terhadap tingkat pengetahuan pekerja seks perempuan di lokalisasi Suko Kabupaten Malang, meskipun tidak signifikan.

3. Faktor dominan lainnya yang mempengaruhi hubungan terpaan media dengan tingkat pengetahuan adalah berupa usia, pendapatan, tingkat pendidikan serta lama pekerja seks perempuan bekerja di lokalisasi. 
4. Hasil penelitian ini proses komunikasi yang terjadi bisa dilihat melalui hubungan antara terpaan media KIE (leaflet dan sticker) dengan tingkat pengetahuan. Begitu juga dengan teori terpaan dan pengetahuan, bahwa hubungan terpaan media dengan pengetahuan juga dipengaruhi oleh usia, tingkat pendidikan, pendapatan dan lama bekerja.

\section{Saran}

Adapun saran dalam penelitian kali ini adalah sebagai berikut:

1. Agar tingkat pengetahuan pekerja seks perempuan tentang penanggulangan HIV dan AIDS menjadi sangat tinggi, maka seharusnya pendamping memberikan terpaan media KIE penanggulangan HIV dan AIDS dengan frekuensi yang tinggi pula, karena hasil penelitian menyatakan bahwa terpaan media KIE yang mereka terima adalah sedang.

2. Mengingat tingkat pengetahuan pekerja seks yang tinggi, maka perlu diadakan media jenis lain untuk semakin menambah dan menjaga tingkat pengetahuan mereka, agar tidak terjadi kejenuhan pada pekerja seks perempuan di lokalisasi Suko Kabupaten Malang.

3. Untuk kajian yang selanjutnya maka perlu dikaji faktor-faktor yang lebih dominan yang mempengaruhi hubungan terpaan media KIE penanggulangan HIV dan AIDS (leaflet dan sticker) dengan tingkat pengetahuan pekerja seks perempuan.

4. Memunculkan media KIE yang ideal untuk meningkatkan pekerja seks perempuan yang berbasis latar belakang pendidikan, usia, pendapatan dan lama mereka bekerja di lokalisasi Suko. Hal ini dilakukan agar komunikasi kesehatan yang terjadi antara pendamping dengan dampingan berjalan efektif dan terjadi perubahan pengetahuan, sikap serta prilaku.

\section{DAFTAR PUSTAKA}

\section{Buku dan Jurnal:}

Azwar, Saifuddin. 2010. Sikap manusia: Teori dan Pengukurannya Edisi ke 2. Yogyakarta: Pustaka Pelajar.

Fidyaningsih, Astri. 2011. Skripsi: Keefektifan media leaflet dan sticker terhadap perubahan tingkat pengetahuan dan perilaku waria dalam upaya pencegahan HIV dan AIDS Di Himpunan Waria Solo (Hiwaso). Surakarta. FKM Universitas Muhammadyah.

Fiske, John. 2011. Cultural and Communication Studies: Sebuah Pengantar Paling Komperhensif. Yogyakarta: Jalasutra.

Fitriani, Sinta. 2011. Promosi Kesehatan. Yogyakarta: Graha Ilmu.

Effendy, Onong Ucjana. 2003. Ilmu, Teori $\&$ Filsafat Komunikasi.Bandung:PT. Citra Aditya Bakti.

Hamidi. 2010. Metode dan Penelitian Teori Komunikasi: Pendekatan Praktis Penulisan Proposal dan Laporan Penelitian. Malang: UMM Press.

Ivancevich, John. M. \& Robert Konopaske. 2006. Perilaku dan Manajemen Organisasi Jilid I: Edisi Ketujuh. Jakarta: Penerbit Erlangga. 
Kriyantono, Rachmat. 2010. Teknik Praktis

Riset

Komunikasi.Jakarta:

Kencana Prenada Media Group.

Lestari, Dwi. 2010. Tesis: Pengaruh pendidikan kesehatan terhadap pengetahuan, sikap dan perilaku PSK dalam rangka pencegahan IMS di lokalisasi Gajah Kumpul Kabupaten Pati. Solo. FKM Universitas Negeri Solo.

Liliweri, Alo. 1991. Memahami Peran Komunikasi Massa Dalam Masyarakat.Bandung: PT. Citra Aditya Bakti.

Littlejohn, W.S. 1996. Theories of Communication. New York: Garland.

Mulyana, Deddy. Ilmu Komunikasi: Suatu Pengantar. Bandung: PT. Remaja Rosdakarya.

Nasution, Zulkarimein. 1990. PrinsipPrinsip Komunikasi Untuk Penyuluhan. Jakarta: Lembaga Penerbit FE UI.

Notoatmodjo, S. 2003. Ilmu Kesehatan Masyarakat. Jakarta: PT. Rineka Cipta.

Notoatmodjo,S. 2005. Metodologi Penelitian Kesehatan Edisi Revisi.Jakarta: PT.Rineka Cipta.

Pratoyo, Bambang. 1995. Tesis: Hubungan Antara Keluarga dan Terpaan Media Cetak Dengan Motif Membaca Remaja Pada Majalah Penyebar Semangat. Surabaya. Fisip Universitas Airlangga.

Rahmat, Jalaluddin. 2004. Metode Penelitian Komunikasi. Bandung: PT.Remaja Rosdakarya.

Rahmat, Jalaluddin. 2004. Psikologi Komunikasi. Bandung: PT. Remaja Rosdakarya.
Riyanto, Makmun. 2008. Tesis: Analisis Faktor Yang Mempengaruhi Efektifitas Iklan dan Implikasinya Terhadap Sikap Merk: Studi Kasus Pada Iklan Pounds di Kota Semarang. Semarang. FISIP Universitas Diponegoro.

Sulaiman, Wahid. 2004. Analisis Regresi Menggunakan SPSS: Contoh Kasus dan Pemecahan. Yogyakarta: Penerbit Andi.

Suprapto, Tommy dan Fahrianoor. 2004. .Komunikasi Penyuluhan: Dalam Teori dan Praktek. Yogyakarta: Arti Bumi Intaran.

Sugiyono. 1999. Statistika Untuk Penelitian. Bandung: CV. Alfabeta.

Sutaryo. 2005. Sosiologi Komunikasi: Perspektif Teoritik. Yogyakarta: Arti Bumi Intaran.

West, Richard, \& Lynn H. Turner. 2008. Pengantar Teori Komunikasi: Analisis dan Aplikasi Buku I. Jakarta: Salemba Humanika.

Lembaga Paramitra Indonesia. 2011. Data Survey Tentang Populasi Pekerja Seks Perempuan di Lokalisasi Kabupaten Malang Tahun 2011. Malang.

Lembaga Paramitra Indonesia. 2011. Data Tahunan Korelasi Pemakaian Kondom dengan ANgka Kejadian IMS Pekerja Seks Perempuan Dilokalisasi Suko tahun 20032011.Malang.

Lindungi Diri Lindungi Semua. Indonesia: FHI, KPA dan USAID, 2004.

Cara Jitu Mencegah Penularan 
Lian Agustina Setiyaningsih, Korelasi terpaan media kie (komunikasi, informasi dan edukasi) penanggulangan hiv dan aids dengan tingkat pengetahuan pekerja seks perempuan (studi kasus pekerja seks

HIV. Indonesia: FHI, KPA dan

USAID, 2004.

\section{Internet:}

Subuh, H.M. 27 November 2011

http://health.kompas.com/read/20

11/11/26/07522958/Kasus.AIDS.

Tertinggi.di.Jawa.Timur. AIDS

INA, September 2011. Diakses 14

Januari 2015.

Disampaikan oleh Direktur Pengendalian

Penyakit Menular Langsung Kementerian Kesehatan, M. Subuh, dalam keterangan pers di Jakarta, Jumat, 25 November 2011 http://www.tempo.co/read/news/20 11/11/25/173368488/Pengidap-

HIVAids-Indonesia- Mencapai200-Ribu. Diakses 15 Janurai 2015 